\title{
Midterm Results After Abandoning Routine Preemptive Coil Embolization of the Internal Iliac Artery During Endovascular Aneurysm Repair
}

Citation for published version (APA):

t'Mannetje, Y. W., Broos, P. P. H. L., Teijink, J. A. W., Stokmans, R. A., Cuypers, P. W. M., \& van Sambeek, M. R. H. M. (2019). Midterm Results After Abandoning Routine Preemptive Coil Embolization of the Internal lliac Artery During Endovascular Aneurysm Repair. Journal of Endovascular Therapy, 26(2), 238-244. https://doi.org/10.1177/1526602819833068

Document status and date:

Published: 01/04/2019

DOI:

$10.1177 / 1526602819833068$

Document Version:

Publisher's PDF, also known as Version of record

Document license:

Taverne

Please check the document version of this publication:

- A submitted manuscript is the version of the article upon submission and before peer-review. There can be important differences between the submitted version and the official published version of record.

People interested in the research are advised to contact the author for the final version of the publication, or visit the DOI to the publisher's website.

- The final author version and the galley proof are versions of the publication after peer review.

- The final published version features the final layout of the paper including the volume, issue and page numbers.

Link to publication

\footnotetext{
General rights rights.

- You may freely distribute the URL identifying the publication in the public portal. please follow below link for the End User Agreement:

www.umlib.nl/taverne-license

Take down policy

If you believe that this document breaches copyright please contact us at:

repository@maastrichtuniversity.nl

providing details and we will investigate your claim.
}

Copyright and moral rights for the publications made accessible in the public portal are retained by the authors and/or other copyright owners and it is a condition of accessing publications that users recognise and abide by the legal requirements associated with these

- Users may download and print one copy of any publication from the public portal for the purpose of private study or research.

- You may not further distribute the material or use it for any profit-making activity or commercial gain

If the publication is distributed under the terms of Article 25fa of the Dutch Copyright Act, indicated by the "Taverne" license above, 


\title{
Midterm Results After Abandoning Routine Preemptive Coil Embolization of the Internal Iliac Artery During Endovascular Aneurysm Repair
}

Journal of Endovascular Therapy 2019, Vol. 26(2) 238-244

(C) The Author(s) 2019

Article reuse guidelines:

sagepub.com/journals-permissions

DOI: $10.1177 / 1526602819833068$

www.jevt.org

\author{
Yannick W. 't Mannetje, MD ${ }^{1,2}$ (D), Pieter P. H. L. Broos, MD, PhD ${ }^{1,2}$, \\ Joep A. W. Teijink, MD, PhD ${ }^{1,2}$, Rutger A. Stokmans, MD, PhD ${ }^{1,2}$, \\ Philippe W. M. Cuypers, MD, PhD', and Marc R. H. M. van Sambeek, MD, PhD',3
}

\begin{abstract}
Purpose: To analyze the results of endovascular repair of common iliac artery $(\mathrm{CIA})$ aneurysms without preemptive coil embolization of the internal iliac artery (IIA). Materials and Methods: Between January 2010 and July 2016, 79 patients (mean age $74.3 \pm 8.4$ years; 76 men) underwent endovascular repair extending into the external iliac artery owing to a CIA aneurysm. The procedure was performed for a ruptured aneurysm in $22(28 \%)$ patients. Eighty-one IIAs were intentionally covered. The median CIA diameter was $37 \mathrm{~mm}$ (range 20-90). The primary outcomes were the occurrence of type II endoleaks and the incidence of buttock claudication. Results: Five (6\%) patients died within 30 days (4 with ruptured aneurysms and I elective case). Two type II endoleaks originating from a covered IIA were recorded; one required an endovascular intervention because of aneurysm growth. The other patient died of a rupture based on an additional type III endoleak. Mean follow-up was 37.6 \pm 26.3 months. Nineteen (26\%) patients required a secondary intervention. Buttock claudication was reported in 21 (28\%) of 74 patients and persisted after I year in 7. No severe ischemic complications as a result of IIA coverage were recorded, and no revascularization was required during followup. Conclusion: Treatment of CIA aneurysms by overstenting the IIA without preemptive coil embolization is safe and has a low risk of type II endoleak and aneurysm growth. Persisting buttock claudication is rare.
\end{abstract}

\section{Keywords}

abdominal aortic aneurysm, buttock claudication, common iliac artery aneurysm, endoleak, endovascular aneurysm repair, internal iliac artery

\section{Introduction}

Approximately $20 \%$ of patients with an abdominal aortic aneurysm (AAA) have involvement of the iliac arteries. ${ }^{1,2}$ Aneurysms of the common iliac arteries (CIA) impose a challenge in obtaining adequate distal sealing during endovascular aneurysm repair (EVAR). A large proportion of CIA aneurysms can be addressed by using flared iliac limbs. However, when the CIA diameter exceeds the available diameter of the largest iliac limbs or the length of the sealing zone is insufficient, the stent-graft must be extended into the external iliac artery (EIA) to ensure proper aneurysm exclusion. An iliac branched device (IBD) could be used, but many patients are not eligible for an IBD based on the instructions for use. ${ }^{3}$

Extension of a stent-graft into the EIA means covering the internal iliac artery (IIA), which may lead to type II endoleak. Therefore, preventive occlusion of the IIA is often favored over straightforward coverage. ${ }^{4,5}$ Various occlusion techniques have been developed, but European and American guidelines promote the use of coil embolization as an effective intervention that can be performed on

'Department of Vascular Surgery, Catharina Hospital, Eindhoven, the Netherlands

${ }^{2}$ Department of Epidemiology, CAPHRI Research School, Maastricht University, Maastricht, the Netherlands

${ }^{3}$ Department of CardioVascular Biomechanics, Eindhoven University of Technology, Eindhoven, the Netherlands

Corresponding Author:

Marc R. H. M. van Sambeek, Department of Vascular Surgery, Catharina Hospital, Michelangelolaan 2, P.O. Box 1350, 5602 ZA Eindhoven, the Netherlands.

Email: marc.v.sambeek@catharinaziekenhuis.nl 
the day of graft implantation. ${ }^{4,5}$ However, severe ischemic complications have been reported, especially when coils are placed deep into the IIA. ${ }^{6,7}$

One may hypothesize that a patent IIA will always lead to a type II endoleak, but there is no solid evidence supporting this theory and the subsequent need for preventive measures. When taking into account that coil embolization is a costly intervention, with increased exposure to radiation and contrast agent, its necessity must be investigated.

In 2010, our department implemented a policy that no preemptive coil embolization would be performed whenever stent-graft extension into the EIA was required because other options were impossible or undesirable. After promising short-term results, ${ }^{8}$ this strategy was continued, and we now update the results of our strategy in a larger population with longer follow-up. Our aim was to determine if IIA coverage without preemptive coil embolization is safe and effective during longer follow-up and if it is well tolerated by patients.

\section{Materials and Methods}

\section{Study Design and Patient Population}

The department's prospectively maintained database was interrogated to identify all patients with intentional overstenting of a patent IIA during treatment of a CIA aneurysm between January 2010 and July 2016. Patients with intact and ruptured abdominal aortic aneurysms (AAA) or iliac aneurysms were eligible for inclusion because the study outcomes were related solely to IIA-associated complications.

The decision to cover the IIA was at the discretion of the operating vascular surgeon. In general, indications to cover the IIA were a CIA diameter $\geq 30 \mathrm{~mm}$, an insufficient distal sealing zone, hostile anatomy for an IBD or flared limbs, or emergency repair. All patients were treated by or under the direct supervision of a senior vascular surgeon. Regular follow-up was performed at 1 month, 1 year, and annually thereafter. If the 1-month computed tomography angiography (CTA) scan showed satisfactory position of the stentgraft, follow-up was continued with duplex ultrasound by experienced vascular technicians. CTA follow-up was performed on indication.

Of the 667 endovascular procedures performed in the observation period, the IIA was covered in 102 patients. Twenty-three cases were excluded because extension into the EIA was either accidental or performed to resolve intraoperative complications, such as a distal endoleak or dissection, leaving 79 patients (mean age $74.3 \pm 8.4$ years; 76 men) in which IIA coverage was planned due to a CIA aneurysm (27 patients previously described $\left.{ }^{8}\right)$. An AAA was present in $46(58 \%)$ patients. Twenty-two (28\%) patients
Table I. Baseline Characteristics of the 79 Study Patients.

\begin{tabular}{lc}
\hline Age, y & $74.3 \pm 8.4$ \\
Men & $76 / 79(96)$ \\
Comorbidities & \\
Smoking history & $40 / 77(52)$ \\
Hypertension & $6 I / 78(78)$ \\
Hypercholesterolemia & $49 / 79(62)$ \\
Coronary artery disease & $34 / 78(44)$ \\
Arrhythmia & $24 / 78(31)$ \\
Cerebrovascular disease & $17 / 78(22)$ \\
Peripheral artery disease & $15 / 78(19)$ \\
Diabetes mellitus & $16 / 78(21)$ \\
COPD & $10 / 78(13)$ \\
Previous aortic surgery & $12 / 79(15)$ \\
Ruptured aneurysm & $22 / 79(28)$ \\
ASA classification & \\
II & $30 / 79(38)$ \\
III & $23 / 79(29)$ \\
IV & $4 / 79(5)$ \\
V & $22 / 79(28)$ \\
Aortic morphology & \\
AAA & $46 / 79(58)$ \\
AAA diameter, mm & $60 \pm 18$ \\
CIA diameters, mm $(\mathrm{n}=8 \mathrm{I})$ & $\mathrm{b}$ \\
$\quad$ Maximum & $37(20-90)$ \\
$\quad$ Proximal & $18(9-47)$ \\
Mid & $36(15-90)$ \\
$\quad$ Distal & $18(6-76)$ \\
\hline
\end{tabular}

Abbreviations: AAA, abdominal aortic aneurysm; ASA, American Society of Anesthesiologists; CIA, common iliac artery; COPD, chronic obstructive pulmonary disease; IIA, internal iliac artery.

${ }^{\text {a }}$ Continuous data are presented as the mean \pm standard deviation or median (absolute range); categorical data are given as the number (percentage). Denominators differ owing to missing values.

${ }^{\mathrm{b}}$ Denominator represents covered internal iliac arteries.

had a ruptured aneurysm, 12 iliac, and 10 AAA. Two patients underwent planned bilateral IIA coverage. One patient was wheelchair dependent and previously underwent a total colectomy; the second patient suffered from a ruptured AAA with bilateral CIAAs. In total, there were 81 covered IIAs in the study group. Median CIA aneurysm diameter was $37 \mathrm{~mm}$ (range 20-90). All morphologic characteristics are presented in Table 1.

\section{Data Collection and Outcome Measures}

An experienced vascular surgeon reviewed the preoperative contrast-enhanced CT scans and measured the CIAs at 3 points: directly distal of the aortic bifurcation, middle of the iliac artery, and just proximal of the iliac bifurcation. A CIA with a maximum diameter $\geq 17 \mathrm{~mm}$ in men or $\geq 15 \mathrm{~mm}$ in women was considered aneurysmal. ${ }^{9}$ All CIA measurements and IIA-related complications are reported based on the number of covered IIAs. 
Table 2. Treatment Details and Follow-up Outcomes. ${ }^{a}$

\begin{tabular}{lc}
\hline Stent-grafts & \\
Bifurcated & $62 / 79(79)$ \\
AUI + FFX & $2 / 79(3)$ \\
Iliac limb only & $7 / 79(9)$ \\
Iliac extension & $8 / 79(10)$ \\
Contralateral IIA ( $\mathrm{n}=77)$ & \\
Patent & $69 / 77(90)$ \\
Occluded & $6 / 77(8)$ \\
Unplanned coverage & $2 / 77(3)$ \\
30-day mortality & $5 / 79(6)$ \\
Follow-up, mo (n=74) & $37.6 \pm 26.3$ \\
Buttock claudication & $21 / 74(28)$ \\
Persisting $>$ I y & 7 \\
IIA-related type II endoleak & \\
Secondary intervention & $2 / 75(3)$ \\
Ipsilateral occlusion/stenosis & $19 / 74(26)$ \\
Open conversion & $8 / 19(42)$ \\
Ruptured aneurysm & $5 / 74(7)$ \\
\hline
\end{tabular}

Abbreviations: AUI, aortouni-iliac; FFX, femoral-femoral crossover; IIA, internal iliac artery.

${ }^{a}$ Continuous data are presented as the mean \pm standard deviation; categorical data are given as the number (percentage).

bPlaced as part of a secondary intervention.

'Denominator represents covered internal iliac arteries.

The primary outcomes were the occurrence of IIA-related type II endoleaks and the incidence of buttock claudication. Events were registered based on entries in the patient records, which were reviewed independently by 2 senior vascular surgeons. Referring physicians were contacted if patients continued follow-up outside our center. The national mortality registry was consulted to determine the date of death. The general practitioner was contacted if no data were available in the hospital system on the cause of death.

\section{Statistical Analysis}

Categorical variables are presented as frequencies with percentages. Continuous variables are presented as mean \pm standard deviation or as median and absolute range in case of skewed data. Time-to-event analysis was performed using the Kaplan-Meier method for survival, freedom from any secondary intervention, and freedom from type II endoleak. Estimates are presented with the $95 \%$ confidence interval (CI). The threshold of statistical significance was $p<0.05$. Statistical analyses were performed using SPSS for MAC (version 21; IBM Corporation, Armonk, NY, USA).

\section{Results}

Sixty-two bifurcated stent-grafts were implanted, and 7 CIA aneurysms were treated with iliac limbs only (Table 2). Two aortouni-iliac devices combined with femoral-femoral crossover bypasses were used; the contralateral IIA was patent on the final angiography. In $12(15 \%)$ cases IIA overstenting was part of a secondary intervention; 8 received iliac extensions. There were no intraoperative deaths or conversions to open repair.

\section{Thirty-Day Survival}

Five (6\%) patients died within 30 days of treatment, including $4(18 \%)$ of the 22 patients with a ruptured aneurysm and $1(2 \%)$ of the 57 electively treated EVAR patients. In one of the ruptured aneurysm deaths both IIAs were covered. The electively treated patient died at home 19 days after surgery of an unknown cause.

\section{Outcomes in Follow-up}

The mean follow-up in 74 surviving patients $(75$ covered IIAs) was 37.6 \pm 26.3 months (range 0.4-92.5). One patient refused further follow-up due to deteriorating health after 26.8 months.

Overall survival was estimated for ruptured and intact aneurysm cases separately. The Kaplan-Meier survival estimates at 3 years were $76.9 \%$ ( $95 \%$ CI $68.0 \%$ to $90.3 \%$ ) for intact aneurysms vs $58.7 \%$ (95\% CI $41.5 \%$ to $81.9 \%$ ) for ruptured aneurysms (Figure 1A). Four of the 26 deaths between 30 days and 60 months were aneurysm related. One death was related to the IIA: the patient died of ruptured AAA due to a type III endoleak originating from the limb connection 8 weeks after first documentation of the IIA-associated type II endoleak. Another patient succumbed to rupture caused by a type III endoleak that occurred after an occluded IBD was diagnosed. Another patient, originally treated for a ruptured iliac aneurysm, returned with a ruptured AAA based on an aortic infection for which he previously refused follow-up or treatment. He died due to sepsis after emergency repair. The fourth patient died of multiple organ dysfunction syndrome following conversion to open repair for bilateral limb occlusion 57 days after EVAR.

During follow-up, the maximum CIA diameter on the ipsilateral side was recorded in 71 cases. The mean CIA diameter of the patients with follow-up was $43 \pm 17 \mathrm{~mm}$ at baseline and $36 \pm 20 \mathrm{~mm}$ at last known imaging $(\mathrm{p}<0.01)$. Iliac aneurysm growth was seen in 4 (5\%) patients: 3 had an endoleak other than a type II and 1 patient had an IIArelated type II endoleak.

\section{Complications}

Two (3\%) type II endoleaks originating from the covered IIA were reported during follow-up. The Kaplan-Meier estimates for freedom from any IIA-associated type II endoleak at 1,3 , and 5 years were $100 \%, 98.3 \%(95 \%$ CI $88.2 \%$ to $99.8 \%$ ), and $95.5 \%$ (95\% CI $82.3 \%$ to $98.9 \%$ ), respectively 
(Figure 1B). Both patients had an additional type III endoleak on the ipsilateral side. One patient was mentioned above; the second patient had a ruptured AAA based on a type III endoleak that was resolved by endolining. The rupture occurred 3 weeks after the first report of the type II endoleak, which remained visible after the secondary intervention. A conversion to open repair was performed after multiple attempts to occlude the IIA.

The Kaplan-Meier estimates of freedom from any secondary intervention at 1,3 , and 5 years were $86.7 \%(95 \%$ CI $76.0 \%$ to $92.9 \%), 72.3 \%$ (95\% CI $58.2 \%$ to $82.4 \%$ ), and $64.1 \%$ (95\% CI $46.5 \%$ to $77.2 \%$ ), respectively (Figure $1 \mathrm{~B}$ ). Secondary interventions were required in $19(26 \%)$ patients, predominantly for limb occlusion or symptomatic stenosis ( 8 in the ipsilateral iliac limb). Reinterventions were predominantly endovascular, though 5 patients were converted to open repair. Indications for conversion were stent-graft occlusion without possibility for endovascular revascularization, stent-graft migration, graft infection, false lumen perfusion after type A dissection, and the previously mentioned persistent type II endoleak.

Buttock claudication was initially reported in 21 (28\%) of 74 patients. Symptoms persisted for $>1$ year in 7 patients. In 2 cases the contralateral IIAs were occluded, one due to accidental coverage. The other was coil embolized at another institute for a concomitant IIA aneurysm. Severity of complaints differed greatly, ranging from a pain-free walking distance of 180 meters to over a kilometer. There was only one report of erectile dysfunction. There were no reports of ischemic colitis, gluteal necrosis, or spinal cord ischemia. Patients were advised to start a supervised exercise program if their mobility was restricted by the buttock claudication. No patient required revascularization of the IIA.

\section{Discussion}

Preemptive coil embolization of the IIA is common in endovascular treatment of CIA aneurysms and is recommended practice according to international guidelines. ${ }^{4,5}$ This study was designed to challenge the indication for coil embolization, not to compare embolization vs overstenting. Our data show that abandoning the practice of coil embolization prior to IIA coverage is effective, safe, and well tolerated. Furthermore, the rate of persistent buttock claudication was low; no severe ischemic complications occurred, and there was no need for revascularization of the IIA. In addition to our data there is a growing body of evidence that shows that abandoning preemptive coil embolization in EVAR does not lead to increased type II endoleak rates. ${ }^{10-14}$

To our knowledge there is no scientific evidence that type II endoleaks originating from the IIA are a common risk. Only 2 were encountered in our study, and both patients suffered a ruptured AAA from an additional type III endoleak, of which any causal relationship is unclear. The
$3 \%$ endoleak rate is comparable to other studies that show rates ranging from $0 \%$ to $6.3 \%{ }^{8,10-14}$ Three studies reported endoleaks from a coil embolized IIA ranging in incidence from $1.3 \%$ to $3.8 \% .^{11,14,15}$ It is questionable if such a low risk of developing a type II endoleak justifies preemptive coil embolization in all patients as the procedure does not offer a $100 \%$ success rate. Furthermore, type II endoleaks are a challenging entity because their clinical significance is equally questionable at the aortic level. ${ }^{10,16}$ Even though the overall type II endoleak rate after EVAR ranges from $8 \%$ to $44 \%$, preemptive coil embolization of lumbar or mesenteric arteries is not common practice. ${ }^{16}$ Abandoning coil embolization is not without type II endoleaks; however, the incidence is low and the application of preventive measures provides similar results.

Apart from technical outcomes, clinical consequences are important but often underreported. In our population about a quarter of patients reported buttock claudication but only a few persisted after 1 year. No severe ischemic complications occurred nor was revascularization required. Several studies show similar results. ${ }^{17,18}$ In some comparative studies no differences in buttock claudication rates were reported for embolized vs non-embolized IIAs. ${ }^{13,14,19,20}$ Farahmand et $\mathrm{al}^{11}$ reported rates of $58 \%$ vs $28 \%(\mathrm{p}=0.01)$ in favor of simple coverage. Coils that are placed too distally increase the risk and severity of ischemic complications. ${ }^{7,11,18}$ Occlusion of an IIA is associated with a significant risk of temporary buttock claudication; malposition of coils increases this risk and severity of persistent complications compared with straightforward coverage. .,11,18,20 $^{2}$

Alternative strategies designed to cope with hostile iliac arteries and maintain pelvic perfusion have been proven effective. However, the complexity of these procedures reduces the applicability and success rate. ${ }^{3,21,22}$ Besides technical and clinical considerations, IBDs have similar drawbacks as those of coil embolization. They require additional fluoroscopy and contrast use and increase the costs of a standard EVAR substantially. We believe that IIA coverage without preemptive coil embolization should be considered if IIA patency cannot be maintained. In general, simple coverage is an effective solution that can be widely applied.

In addition to symptoms and complications directly related to the IIA, about a quarter of patients required a secondary intervention. It has been previously described that patients with concomitant iliac aneurysms had an increased risk of complications. ${ }^{2}$ Occlusion or stenosis of the ipsilateral iliac limb was the indication to intervene in over a third of cases that required a secondary intervention. It is likely that this rate of occlusion is not related to the presence or absence of coil embolization but is associated with the landing of the stent-graft in the EIA. Landing in the EIA is a strong and independent predictor of limb occlusion regardless the type of stent-graft. ${ }^{23-25}$ The increased risk of occlusion is most likely related to the reduced diameter and 

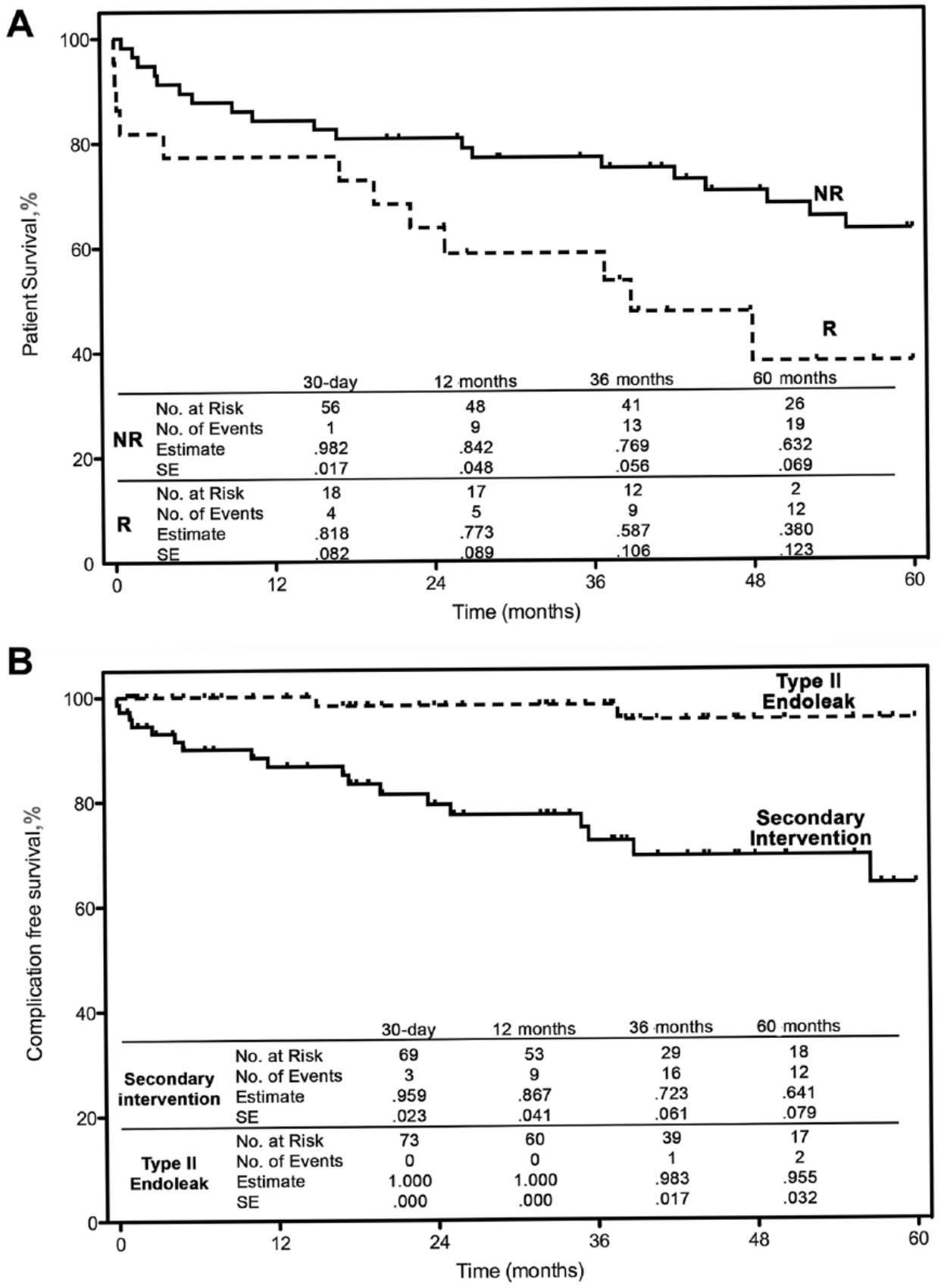

Figure I. Kaplan-Meier curves representing (A) patient survival [ruptured (R) vs non-ruptured (NR) aneurysm] and (B) freedom from reintervention and from type II endoleak associated with the covered internal iliac artery. SE, standard error.

increased tortuosity of EIAs. ${ }^{25}$ Therefore, it is important that patients are informed of the increased risk of limb occlusion and instructed to contact their physician.

\section{Limitations}

First, there was no coil embolized IIA group, so failure rates cannot be compared to show noninferiority. Although the data retrieval was aimed at the outcomes of IIA coverage and the clinical outcomes, no standardized questionnaires were used to contact the patients directly. This might lead to an underreporting of buttock claudication and especially erectile dysfunction. However, symptoms that were severe or required treatment were reported in the medical records. These limitations could be overcome by a randomized controlled trial that compares embolization to coverage and 
systematically records symptoms. However, our results combined with the current literature give reason to reconsider current practice.

\section{Conclusion}

Treatment of CIA aneurysms by intentional overstenting of the IIA without preemptive coil embolization is safe and has a low risk for the development of type II endoleaks. Buttock claudication rarely persists after 1 year.

\section{Declaration of Conflicting Interests}

The author(s) declared no potential conflicts of interest with respect to the research, authorship, and/or publication of this article.

\section{Funding}

The author(s) disclosed receipt of the following financial support for the research, authorship, and/or publication of this article: The Department of Vascular Surgery of the Catharina Hospital funded the composition of this article.

\section{ORCID iD}

Yannick W. 't Mannetje (iD https://orcid.org/0000-0002-7287 $-0705$

\section{References}

1. Armon MP, Wenham PW, Whitaker SC, et al. Common iliac artery aneurysms in patients with abdominal aortic aneurysms. Eur J Vasc Endovasc Surg. 1998;15:255-257.

2. Hobo R, Sybrandy JE, Harris PL, et al. Endovascular repair of abdominal aortic aneurysms with concomitant common iliac artery aneurysm: outcome analysis of the EUROSTAR Experience. J Endovasc Ther. 2008;15:12-22.

3. Gray D, Shahverdyan R, Jakobs C, et al. Endovascular aneurysm repair of aortoiliac aneurysms with an iliac sidebranched stent graft: studying the morphological applicability of the Cook device. Eur J Vasc Endovasc Surg. 2015;49: 283-288.

4. Moll FL, Powell JT, Fraedrich G, et al Management of abdominal aortic aneurysms clinical practice guidelines of the European Society for Vascular Surgery. Eur J Vasc Endovasc Surg. 2011;41(suppl 1):S1-S58.

5. Chaikof EL, Brewster DC, Dalman RL, et al. SVS practice guidelines for the care of patients with an abdominal aortic aneurysm: executive summary. J Vasc Surg. 2009;50: 880-896.

6. Chitragari G, Schlosser FJ, Ochoa Chaar CI, et al. Consequences of hypogastric artery ligation, embolization, or coverage. J Vasc Surg. 2015;62:1340-1347.e1.

7. Cynamon J, Lerer D, Veith FJ, et al. Hypogastric artery coil embolization prior to endoluminal repair of aneurysms and fistulas: buttock claudication, a recognized but possibly preventable complication. J Vasc Interv Radiol. 2000;11: 573-577.
8. Stokmans RA, Willigendael EM, Teijink JA, et al. Challenging the evidence for pre-emptive coil embolisation of the internal iliac artery during endovascular aneurysm repair. Eur J Vasc Endovasc Surg. 2013;45:220-226.

9. Johnston KW, Rutherford RB, Tilson MD, et al. Suggested standards for reporting on arterial aneurysms. Subcommittee on Reporting Standards for Arterial Aneurysms, Ad Hoc Committee on Reporting Standards, Society for Vascular Surgery and North American Chapter, International Society for Cardiovascular Surgery. J Vasc Surg. 1991;13: 452-458.

10. Papazoglou KO, Sfyroeras GS, Zambas N, et al. Outcomes of endovascular aneurysm repair with selective internal iliac artery coverage without coil embolization. J Vasc Surg. 2012;56:298-303.

11. Farahmand P, Becquemin JP, Desgranges P, et al. Is hypogastric artery embolization during endovascular aortoiliac aneurysm repair (EVAR) innocuous and useful? Eur J Vasc Endovasc Surg. 2008;35:429-435.

12. Lee CW, Kaufman JA, Fan CM, et al. Clinical outcome of internal iliac artery occlusions during endovascular treatment of aortoiliac aneurysmal diseases. $J$ Vasc Interv Radiol. 2000;11:567-571.

13. Rajesparan K, Partridge W, Refson J, et al. The risk of endoleak following stent covering of the internal iliac artery during endovascular aneurysm repair. Clin Radiol. 2014;69:1011-1018

14. Stokmans RA, Broos P, van Sambeek M, et al. Overstenting the hypogastric artery during endovascular aneurysm repair with and without prior coil embolization: a comparative analysis from the ENGAGE Registry. J Vasc Surg. 2018;67: 134-141.

15. Heye S, Nevelsteen A, Maleux G. Internal iliac artery coil embolization in the prevention of potential type 2 endoleak after endovascular repair of abdominal aortoiliac and iliac artery aneurysms: effect of total occlusion versus residual flow. J Vasc Interv Radiol. 2005;16(2 pt 1):235-239.

16. Sidloff DA, Stather PW, Choke E, et al. Type II endoleak after endovascular aneurysm repair. Br J Surg. 2013;100: $1262-1270$.

17. Rayt HS, Bown MJ, Lambert KV, et al. Buttock claudication and erectile dysfunction after internal iliac artery embolization in patients prior to endovascular aortic aneurysm repair. Cardiovasc Intervent Radiol. 2008;31:728-734.

18. Mehta M, Veith FJ, Ohki T, et al. Unilateral and bilateral hypogastric artery interruption during aortoiliac aneurysm repair in 154 patients: a relatively innocuous procedure. $J$ Vasc Surg. 2001;33(2 suppl):S27-S32.

19. Luo H, Huang B, Yuan D, et al. 8-Year long-term outcome comparison: two ways to exclude the internal iliac artery during endovascular aorta repair (EVAR) surgery. PLoS One. 2015;10:e130586.

20. Wyers MC, Schermerhorn ML, Fillinger MF, et al. Internal iliac occlusion without coil embolization during endovascular abdominal aortic aneurysm repair. J Vasc Surg. 2002;36:1138-1145.

21. Karthikesalingam A, Hinchliffe RJ, Holt PJ, et al. Endovascular aneurysm repair with preservation of the inter- 
nal iliac artery using the iliac branch graft device. Eur J Vasc Endovasc Surg. 2010;39:285-294.

22. Loth AG, Rouhani G, Gafoor SA, et al. Treatment of iliac artery bifurcation aneurysms with the second-generation straight iliac bifurcated device. J Vasc Surg. 2015;62:1168-1175.

23. Faure EM, Becquemin JP, Cochennec F, et al. Predictive factors for limb occlusions after endovascular aneurysm repair. $J$ Vasc Surg. 2015;61:1138-1145.e2.
24. Carroccio A, Faries PL, Morrissey NJ, et al. Predicting iliac limb occlusions after bifurcated aortic stent grafting: anatomic and device-related causes. J Vasc Surg. 2002;36: 679-684.

25. Conway AM, Modarai B, Taylor PR, et al. Stent-graft limb deployment in the external iliac artery increases the risk of limb occlusion following endovascular AAA repair. $J$ Endovasc Ther. 2012;19:79-85. 